\title{
Espacialidad urbana y educación geográfica
}

Moreno, N. (2019).

Espacialidad urbana y educación geográfica.

Bogotá: Universidad Pedagógica Nacional.

Reseńa elaborada por: Elsa Amanda Rodríguez de Moreno

El libro, con los resultados de la investigación realizada por la doctora Nubia Moreno Lache, toma como pretexto la localidad de Chapinero en Bogotá para aplicar una novedosa forma de analizar el espacio: integrar la teoría geográfica con la literatura para interpretar la espacialidad de la ciudad y hacer de esta un recurso didáctico importante en la educación geográfica. Yo, que estudié hace cuatro décadas la teoría geográfica en unos textos voluminosos y pesados, no solo física, sino gramaticalmente hablando, envidio a las nuevas generaciones por el hecho de contar con textos, al menos, que parten de la realidad y el entorno en el cual se vive, aplicando la teoría e interpretándola de manera que es fácil comprender los conceptos abstractos y científicos en nuestro espacio inmediato. En la medida en que avanzo en la lectura del libro me llama la atención los numerosos conceptos que se logran trabajar en cada capítulo (expansión, renovación urbana, congestión, territorialidades), como también conceptos emergentes que surgen de teorías geográficas que tienen en cuenta la subjetividad, experiencias, vivencias, mirada y valoración del espacio que enriquecen el cúmulo de conocimientos geográficos y facilitan a lectores y estudiantes la comprensión del espacio.

El primer capítulo, "Indagar espacios y espacialidades en la ciudad", inicia especificando que la didáctica geográfica se reflexiona desde la mirada epistemológica de la geografía humanística, particularmente desde las geografías de la vida cotidiana. En el mismo capítulo se explica la razón e importancia educativa de estudiar el espacio y la espacialidad desde la perspectiva de la cotidianidad a partir de la novela urbana referida al barrio de Chapinero, debido a que la literatura expresa lugares, interacciones y construcciones sociales que demuestran su carácter dinámico. Dado que el fin de este estudio es aplicarlo en la educación geográfica, se argumenta la importancia de este nuevo enfoque para lograr la comprensión de la ciudad en sus dimensiones socioculturales y socioespaciales, más allá de la descripción biofísica que ha sido la mirada predominante. Asimismo, se explican las razones por las cuales se selecciona el barrio de Chapinero como espacio idóneo para analizarlo desde las perspectivas ya señaladas, en particular, por su función de bisagra entre centro y sur de la ciudad, sus hitos arquitectónicos, su dinamismo y su significado en el reconocimiento y el reconocerse al interior de la capital.

El segundo capítulo, "La ciudad un texto como pretexto para la educación geográfica”, es el que expone el soporte teórico de la disertación planteada desde la geografía, la literatura y la didáctica, trípode que sostiene la investigación realizada y que se socializa a través de este libro. La doctora Moreno inicia explicando el enfoque geográfico y las razones de la selección, las ventajas para el estudio que se propuso realizar y los pensadores con cuyos pensamientos se identifica (particularmente con Yi- Fu Tuan). Asimismo, la autora teje finamente la relación entre diferentes posturas geográficas relacionadas, tales como la geografía de la percepción, la geografía del comportamiento y la legibilidad de la ciudad, explicando y valorando lo relacionado con su problema de investigación aterrizado en las geografías de la vida cotidiana, que es la base que soporta todo el trabajo.

Por otro lado, en "La ciudad fuente de educación espacial: lecturas e interpretaciones", los lectores van a encontrar lo más interesante, especialmente para los educadores, puesto que incluye las pautas para analizar el barrio de Chapinero con base en los aportes de la novela Angosta de Héctor Abad Faciolince, complementado con la identificación de los lugares significativos, la concurrencia de las personas y las 
encuestas realizadas a habitantes del barrio. Recomiendo analizar con cuidado, tanto desde el punto de vista geográfico como educativo, la matriz elaborada para analizar el barrio con base en la novela.

Obviamente, cuando se elabora una tesis doctoral se debe demostrar el conocimiento de grandes enfoques, escuelas y líneas de investigación para sustentar teóricamente el análisis del problema, que resulta bastante difícil en cualquier disciplina científica, pero aún más en geografía, no por ser muy larga su trayectoria, sino porque es muy difícil dilucidar y separar lo geográfico de lo sociológico, de lo psicológico, lo espacial de lo social (porque es un binomio inseparable), de lo antropológico. No obstante, la doctora Moreno demuestra una gran habilidad intelectual para tomar de cada postura epistemológica tradicional o contemporánea, de cada urbanista, arquitecto o sociólogo, únicamente aquello que es pertinente para explicar el problema de investigación, lo cual demuestra una claridad de cada una de las partes analizadas en el trabajo: el espacio-espacialidad, la novela y la educación geográfica.

Debo destacar un inconveniente más para la autora, el hecho de que es la primera tesis con unas características tan particulares como la suya. En Colombia, aunque hay estudios cortos, ponencias, artículos escritos desde la mirada de las geografías personales, desde la geografía de la percepción, desde la geografía del comportamiento, como tesis doctoral no conozco antecedentes. Este hecho implica varias dificultades, entre ellas, la inexistencia de tutores con la experiencia para dirigirlas. No hay universidades abiertas a nuevas tendencias, a nuevas metodologías o parámetros, por lo que es necesario reconocer la apertura de la Universidad Pedagógica Nacional. No hay muchos lectores de tesis con mentes abiertas para colaborar en la construcción de nuevas perspectivas en el análisis de la temática planteada, y los lectores como yo no estamos acostumbrados a leer temas tan complejos.

Por consiguiente, el solo hecho de tratar de hacer una reseña, en mi caso, implica un aprendizaje en cuanto a la actualización en los temas en los cuales suelo trabajar. Ahora tengo mis dudas con respecto a qué tan actualizados son los conceptos y contenidos que enseño. De otra parte, me permite valorar mis procesos de pensamiento, de aprendizaje y de enseñanza en cuanto lo estudiado a finales del siglo xx; se escribía en otros términos, se basaba, como lo afirma la doctora Moreno, en lo biofísico - que es mucho más concreto-y seguía unas pautas de escritura lineales. Solo se hablaba de un tema o una rama de la ciencia: geografía, psicología, educación, historia, antropología. Actualmente, un libro puede contener varias disciplinas científicas, lo que para los tradicionalistas es una sorpresa. Pero así es todo lo posmoderno en este siglo xxI: jasombroso! 